\title{
Derivative Spectrophotometric Methods for the Analysis and Stability Studies of Colistin Sulphate
}

\author{
Mohammed Mutasim Elimam, Shaza Wagiealla Shantier, \\ Elrasheed Ahmed Gadkariem, and Magdi Awadalla Mohamed \\ Department of Pharmaceutical Chemistry, Faculty of Pharmacy, University of Khartoum, P.O. Box 1996, Khartoum, Sudan \\ Correspondence should be addressed to Shaza Wagiealla Shantier; sshantier@yahoo.com
}

Received 1 September 2015; Revised 29 November 2015; Accepted 29 November 2015

Academic Editor: Jean-Luc Blin

Copyright (c) 2015 Mohammed Mutasim Elimam et al. This is an open access article distributed under the Creative Commons Attribution License, which permits unrestricted use, distribution, and reproduction in any medium, provided the original work is properly cited.

\begin{abstract}
Simple spectrophotometric methods were developed for the quantitative determination of colistin sulphate in bulk and dosage forms. The methods were based on the measurement of first and second derivative spectra of colistin sulphate at $298 \mathrm{~nm}$ and $318 \mathrm{~nm}$, respectively. Beer's law was obeyed in the concentration range $800-4000 \mathrm{IU} / \mathrm{mL}$ with good correlation coefficient (not less than 0.998 ) for both methods. The developed first derivative spectrophotometric method was then selected to study the degradation behavior of colistin sulphate in alkaline media at different temperatures as the second derivative method failed to give reproducible results for the stability study. The $\mathrm{pH}$-rate profile indicates a first-order dependence of the degradation rate on $\left[\mathrm{OH}^{-}\right]$at $\mathrm{pH}$ ranging between 8 and 11. The obtained results for the photochemical study reflected photostability of colistin sulphate.
\end{abstract}

\section{Introduction}

Colistin (polymyxin E, Figure 1) is a polymyxin antibiotic produced by certain strains of Bacillus polymyxa var. colistinus. Colistin is a mixture of cyclic polypeptides colistins A and B. It is effective against most Gram-negative bacilli and is used as a polypeptide antibiotic. It remains one of the last-resort antibiotics for multidrug-resistant Pseudomonas aeruginosa, Klebsiella pneumoniae, and Acinetobacter [1].

The knowledge of a drug chemical stability is of great importance to select the suitable storage conditions, estimation of drug shelf life, and anticipation of the drug interaction [2].

Literature survey revealed several methods for the determination of colistin sulphate in animals' body fluid and cow milk. These methods include mainly chromatographic methods [3-6]. None of these methods has been applied for the analysis and stability studies of colistin sulphate in dosage forms.

Derivative spectrophotometry has been widely applied in the analysis of different pharmaceutical dosage forms. It solves the problem of analysis associated with drug combination, stability studies of drug and degradation products, drug impurities, and interference of excipients in drugs.

Therefore, the aim of the present work is to develop simple and accurate derivative spectrophotometric methods for the determination of colistin sulphate in bulk and dosage forms and to investigate the effects of $\mathrm{pH}$, temperature, and alkali on its stability.

Experiments

Instrumentation. UV spectrophotometric studies were carried out on Shimadzu UV-1800ENG240V (Kyoto, Japan). The operating conditions were as follows:

(i) Wavelength range: $250-450 \mathrm{~nm}$.

(ii) Scan speed: medium, $0.2 \mathrm{~nm} / \mathrm{s}$.

(iii) Minimum ordinate readings recorded for the absorbance measurement $(-0.005-0.02)$. 


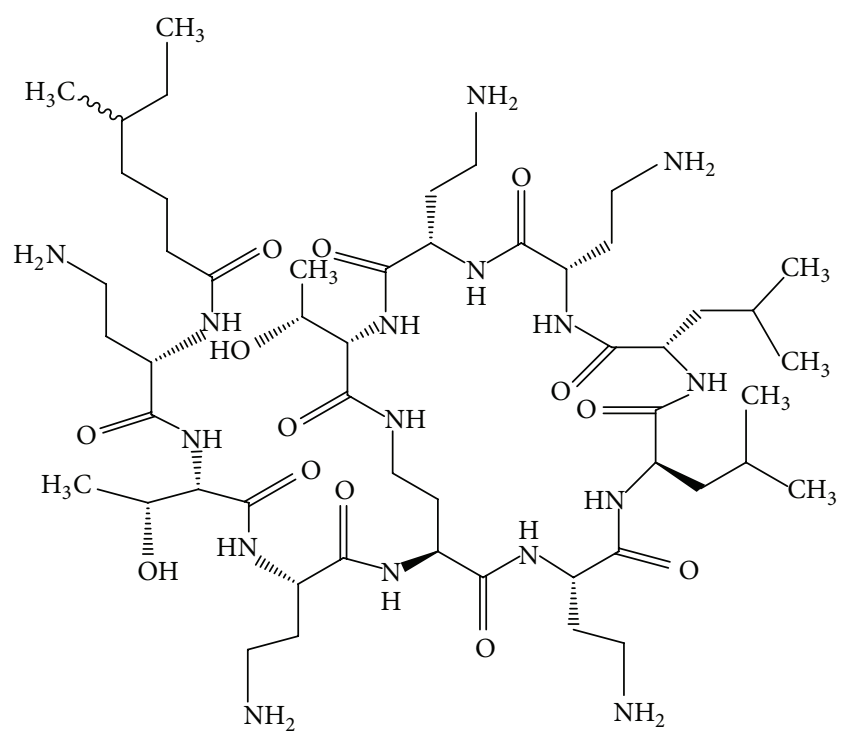

FIGURE 1: Chemical structure of colistin (used as sulphate).

\section{Materials and Methods}

All the materials and reagents used were of analytical grade. Colistin reference standard was obtained from the Central lab, Riyadh, Kingdom of Saudi Arabia. Colistin sample (Colidad powder; each 1 gram colistin (as sulphate) contains 800,000 IU) was obtained from Dar Aldawa Pharmaceuticals, Jordan. Disodium orthophosphate and sodium hydroxide were obtained from British Drug House (BDH), Poole, England; Mcllvaine universal buffer ( $\mathrm{pH}$ range 2.2-8) [7] and phosphate buffer (pH range 9-11) [8] were prepared.

2.1. Preparation of Standard Stock Solution. One gram of colistin sulphate standard was accurately weighed and transferred into $100 \mathrm{~mL}$ volumetric flask. The volume was completed to mark with distilled water (solution A; $8000 \mathrm{IU} / \mathrm{mL}$ ).

2.2. Preparation of Sample Stock Solution. An amount of the powdered sample equivalent to $800,000 \mathrm{IU}$ was accurately weighed and transferred into $100 \mathrm{~mL}$ volumetric flask. The volume was then completed to mark with distilled water (solution B; $8000 \mathrm{IU} / \mathrm{mL}$ ).

\section{Method Validation}

3.1. Linearity. Serial dilutions were made from solution A by transferring accurately measured volumes $(1-5 \mathrm{~mL})$ to set of $10 \mathrm{~mL}$ volumetric flasks. The volumes were completed to mark with distilled water. The first and second derivative spectra were recorded over the range $250 \mathrm{~nm}-450 \mathrm{~nm}$. The calibration curve was constructed by plotting the obtained absorbance values against drug concentrations in $\mathrm{IU} / \mathrm{mL}$.

$3 \mathrm{~mL}$ of solution $\mathrm{B}$ was treated as under linearity. The content of the powdered sample can be determined from the regression data or by the direct comparison of sample/standard concentrations.
3.2. Precision. Within-day and between-day data were determined for three concentrations within the linearity range. The precision was then estimated in terms of relative standard deviation \% (RSD\%).

3.3. Accuracy. The accuracy of the developed method was determined by means of recovery study. Two $\mathrm{mL}$ of each of the solutions A and B was transferred into two separate stoppered glass tubes. In a third stoppered glass tube, $2 \mathrm{~mL}$ of solution A and $2 \mathrm{~mL}$ of solution B were mixed. Solutions in the three tubes were treated as under linearity and the percent recovery was calculated using the reported formula [9]:

$$
\frac{A_{\text {mix }}-A_{\text {sam }}}{A_{\text {std }}} \times 100,
$$

where $A_{\text {mix }}$ is the absorbance of the mixture solution, $A_{\text {sam }}$ is the absorbance of the sample solution, and $A_{\text {std }}$ is the absorbance of the standard solution.

3.4. Limits of Detection and Quantification. LOD and LOQ were determined using the following formulae [10]:

$$
\begin{aligned}
& \mathrm{LOD}=\frac{3.3 \delta}{S}, \\
& \mathrm{LOQ}=\frac{10 \delta}{S},
\end{aligned}
$$

where $\delta$ is the standard deviation of the intercept of the regression line; $S$ is the slope of the calibration line.

\section{Stability Studies}

4.1. Effect of $p H$ on the Stability of Colistin Solution. Aliquots of solution A $(3 \mathrm{~mL})$ were transferred into a set of volumetric flasks $(10 \mathrm{~mL})$. One $\mathrm{mL}$ of the phosphate buffers was added to each flask to obtain a range of $\mathrm{pH}$ values $(2.2,3,4,5$, $6,7,8,9,10$, and 11). The volumes were completed to mark with distilled water. The kinetics of drug degradation was then monitored at 5-minute intervals using the developed first derivative spectrophotometric method. The rate constant for each reaction mixture was calculated from the plot of $\%$ remaining drug versus time interval [11].

4.2. Effect of Alkali and Acid on the Stability of Colistin Solution. Three $\mathrm{mL}$ of solution A was transferred into $10 \mathrm{~mL}$ volumetric flask. $1 \mathrm{~mL}$ of $1 \mathrm{M} \mathrm{NaOH}$ was added, and the volume was completed to mark with distilled water. The drug degradation was monitored at 5-minute intervals using the developed first derivative spectrophotometric method (250$450 \mathrm{~nm})$.

The same procedure was repeated adding $1 \mathrm{~mL}$ of $1 \mathrm{M} \mathrm{HCl}$ instead of $\mathrm{NaOH}$ to study the effect of acid on stability of colistin sulphate.

4.3. Effect of Temperature on the Stability of Colistin Solution. Aliquots from solution A $(3 \mathrm{~mL})$ were transferred into four stoppered glass tubes. $1 \mathrm{~mL}$ of Mcllvaine universal buffer 


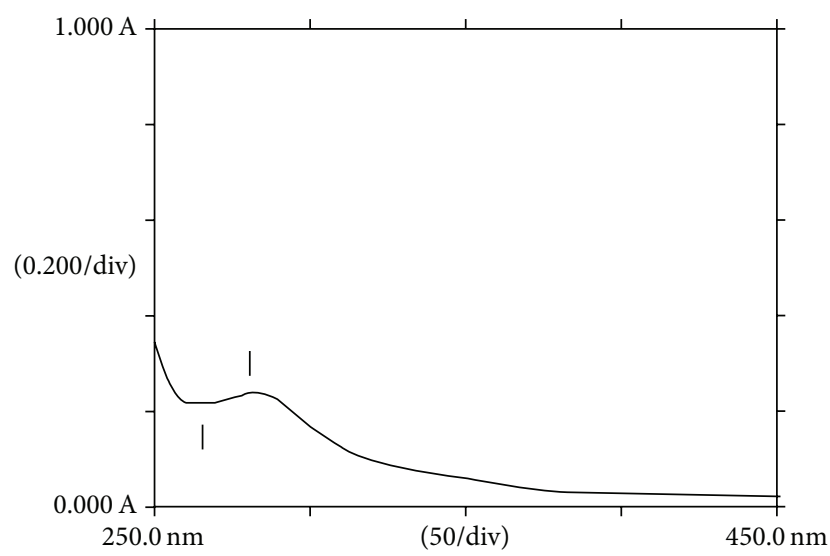

FIGURE 2: UV spectrum of colistin solution $(280 \mathrm{~nm}, 1600 \mathrm{IU} / \mathrm{mL})$.

( $\mathrm{pH} 9$ ) was added to each tube. The volume of the first tube was completed to $10 \mathrm{~mL}$ with distilled water and the first derivative spectra were recorded at room temperature $\left(25^{\circ} \mathrm{C}\right)$ with time intervals ranging within 5-20 minutes. The other three tubes were heated at $40^{\circ} \mathrm{C}$ at the same time interval. The reaction was then quenched by cooling and the volumes were completed to $10 \mathrm{~mL}$ with distilled water. The kinetics of the degradation was monitored using the developed method (250-450 nm).

4.4. Effect of Light on the Stability of Colistin Solution. The effect of sunlight in the day time was studied by placing colistin solution in stoppered glass tube $(3 \mathrm{~mL}$ of solution A completed to $10 \mathrm{~mL}$ with distilled water; $2400 \mathrm{IU} / \mathrm{mL}$ ) and exposed to sunlight. The photodegradation was then monitored by the developed method at time intervals ranging within 1-6 hrs.

\section{Results and Discussion}

Direct spectrophotometric methods (zero-order) are widely used in pharmaceutical analysis although they lack selectivity and did not prove in most cases to be a useful tool in stability-indicating procedure. However, the development of derivative spectroscopy presented the analyst with a tool suited for the analysis of different pharmaceutical dosage forms as it has proved to be an accurate stability-indicating method. Therefore, our main objective was to develop an accurate and precise method for the analysis of colistin sulphate which can also be applied for the stability studies under stress conditions as per ICH requirements [12].

The original UV spectrum of colistin solution showed a broad peak at $280 \mathrm{~nm}$ (Figure 2). First and second derivative spectra showed sharper and better resolved peaks at $298 \mathrm{~nm}$ and $318 \mathrm{~nm}$, respectively (Figures 3 and 4).

5.1. Linearity. A calibration curve was prepared using the developed method at concentration of $800-4000 \mathrm{IU} / \mathrm{mL}$ for colistin with correlation coefficient value not less than 0.998 . The regression analysis data was calculated at $95 \%$ confidence

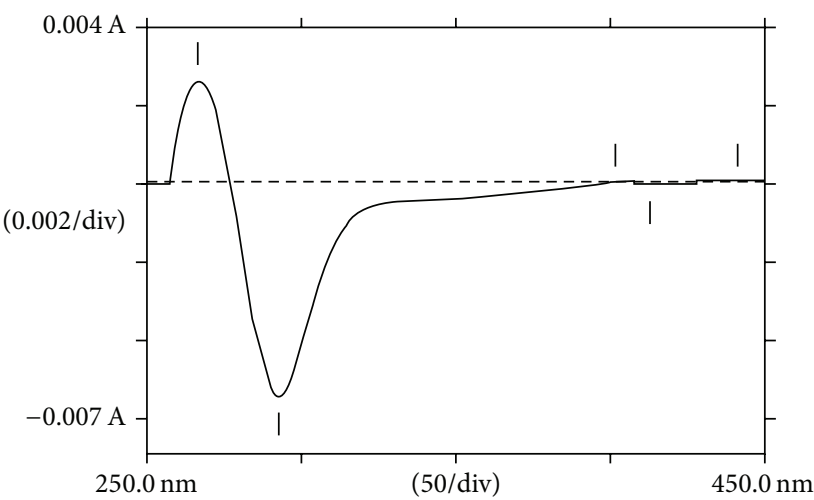

FIGURE 3: First derivative spectrum of colistin solution $(298 \mathrm{~nm}$, $1600 \mathrm{IU} / \mathrm{mL})$.

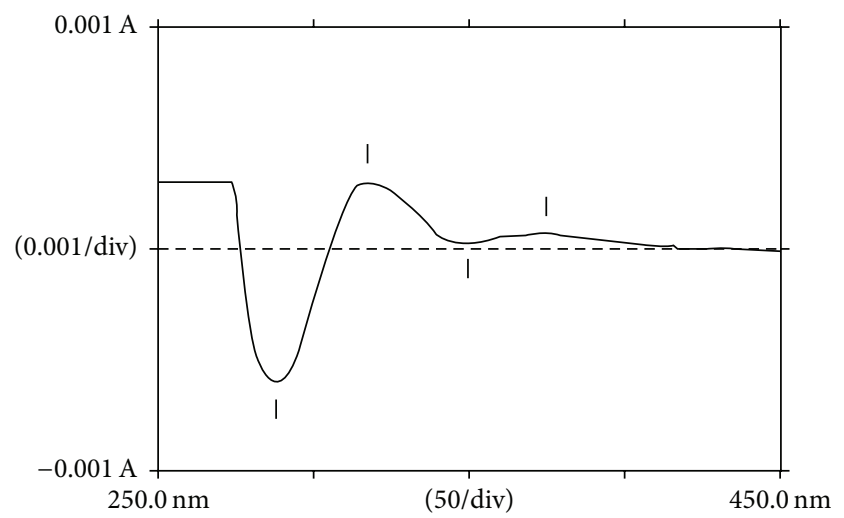

FIGURE 4: Second derivative spectrum of colistin solution $(318 \mathrm{~nm}$, $2400 \mathrm{IU} / \mathrm{mL})$.

level for the developed methods using the following formulae [10]:

$$
\begin{aligned}
& \left(b \pm t s_{b}\right), \\
& \left(a \pm t s_{a}\right),
\end{aligned}
$$

where $b$ is the slope, $a$ the intercept, $s_{b}$ standard deviation of slope, and $s_{a}$ standard deviation of intercept and the $t$-value is at $95 \%$ confidence level for $(n-2)$. The results obtained reflected the consistency of the prepared calibration graphs (Table 1).

The developed derivative spectrophotometric methods were applied for the drug uniformity testing in colistin powder where good assay results were obtained $(98.8 \pm 1.8 \%$, $n=3)$.

5.2. Accuracy and Precision. The accuracy of the procedure and freedom of interference by the powder excipients were confirmed by the results obtained for recovery testing of added amount of authentic colistin to sample solution in the ratio of $1: 1$. The results showed good recovery $(99.7 \pm$ $1.6 \%, n=3$ ), which indicates the accuracy of the developed method. 
TABLE 1: Linearity data for the developed methods.

\begin{tabular}{lccc}
\hline Parameter & Zero-order & 1st derivative & 2nd derivative \\
\hline$\lambda_{\max }$ & $280 \mathrm{~nm}$ & $298 \mathrm{~nm}$ & $318 \mathrm{~nm}$ \\
Slope $\pm t s_{b}$ & $0.00027 \pm 0.000$ & $0.000005 \pm 0.000$ & $0.0089 \pm 0.0008$ \\
Inter. $\pm t s_{a}$ & $0.015 \pm 0.089$ & $-0.0006 \pm 0.0017$ & $-0.43 \pm 2.7$ \\
$\mathrm{LOD}$ & $335 \mathrm{IU} / \mathrm{mL}$ & $343 \mathrm{IU} / \mathrm{mL}$ & $239 \mathrm{IU} / \mathrm{mL}$ \\
$\mathrm{LOQ}$ & $1015 \mathrm{IU} / \mathrm{mL}$ & $1040 \mathrm{IU} / \mathrm{mL}$ & $725 \mathrm{IU} / \mathrm{mL}$ \\
$R$ & 0.998 & 0.998 & 0.999 \\
\hline
\end{tabular}

TAble 2: Precision of the developed methods.

\begin{tabular}{lcc}
\hline \multirow{2}{*}{ Concentration $(\mathrm{IU} / \mathrm{mL})$} & \multicolumn{2}{c}{ RSD\%; $n=3$} \\
& Within-day & Between-day \\
\hline 1600 & 1.1 & 2 \\
2400 & 0.54 & 1.3 \\
3200 & 0.77 & 0.8 \\
\hline
\end{tabular}

TABLE 3: $K_{\mathrm{obs}}, t_{1 / 2}$, and $t_{90}$ values for the degradation of colistin sulphate at room temperature in different $\mathrm{pH}$ values.

\begin{tabular}{lccc}
\hline $\mathrm{pH}$ & $K_{\mathrm{obs}} \mathrm{min}^{-1}$ & $t_{1 / 2} \min$ & $t_{90}$ \\
\hline $2.2-7.4$ & 0.0028 & 247.50 & 37.50 \\
8 & 0.0050 & 138.60 & 21.00 \\
9 & 0.0079 & 87.70 & 13.30 \\
10 & 0.0115 & 60.30 & 9.13 \\
11 & 0.0200 & 34.65 & 5.25 \\
\hline
\end{tabular}

The precision of the developed method was confirmed by the calculated RSD values, which were found to be within the accepted limit (less than 2\%) (Table 2).

\subsection{Stability Studies}

5.3.1. Effect of $p H$. The degradation of colistin at different $\mathrm{pH}$ values ranging within 2.2-11 was monitored by the developed first derivative spectrophotometric method. A plot of $\log K_{\text {obs }}$ (degradation rate constant) versus $\mathrm{pH}$ values gave a positive slope on the alkaline side. This suggested first order dependence of the degradation rate on $\left[\mathrm{OH}^{-}\right]$. The obtained $\mathrm{pH}$ profile (Figure 5) resembles subtype BCD in the generalized $\mathrm{pH}$ polygon [11], where $K_{\mathrm{obs}}$ increases, and hence $t_{1 / 2}$ decreases, at high $\mathrm{pH}$ values (Table 3 ).

5.3.2. Effect of Alkali. The effect of different alkali concentrations with different time intervals on the degradation rate of colistin sulphate solution was studied using the developed first derivative method. $1 \mathrm{M} \mathrm{NaOH}$ with 5 -minute intervals was found appropriate to give good correlation coefficient with measurable degradation rate. The first derivative spectrum of colistin solution treated with $1 \mathrm{M} \mathrm{NaOH}$ showed a decrease in colistin sulphate peak at $298 \mathrm{~nm}$ with the consequent appearance of major degradation peak at $338 \mathrm{~nm}$ (Figure 6).

The degradation rate constant was calculated by plotting log \% remaining drug versus time interval (Figure 7).

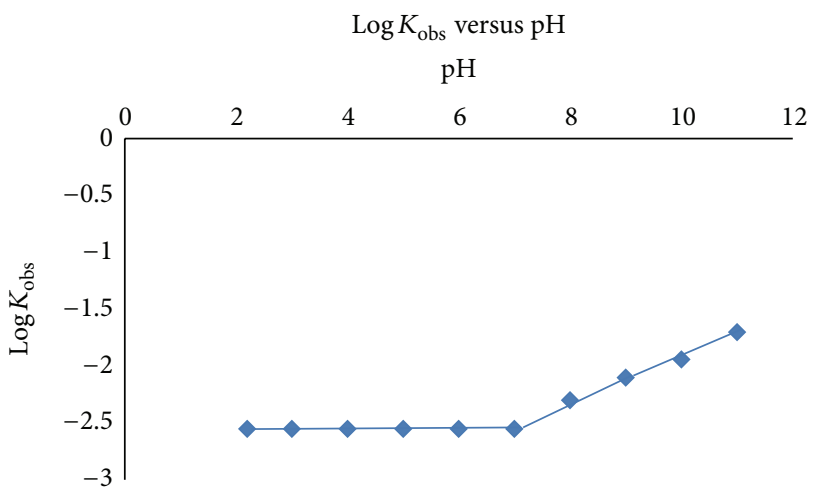

FIGURE 5: $\mathrm{pH}$ profile of colistin degradation at room temperature.

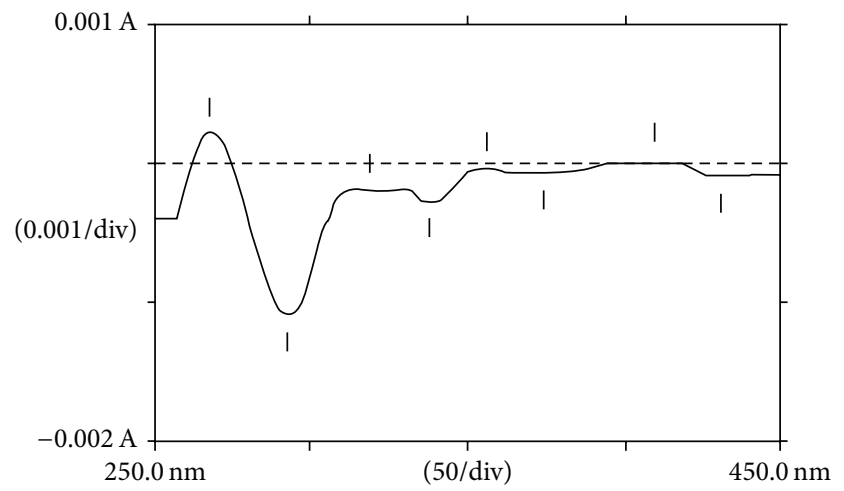

FIGURE 6: First derivative spectrum of colistin solution treated with $1 \mathrm{M} \mathrm{NaOH}$ for 15 minutes.

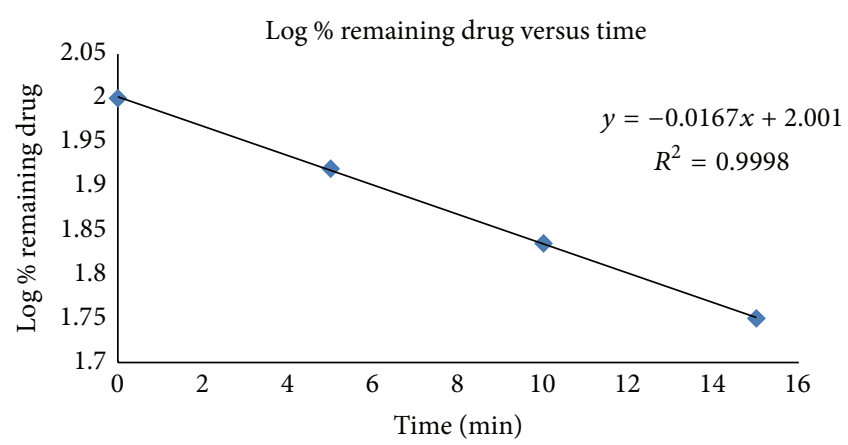

Figure 7: Effect of $\mathrm{NaOH}(1 \mathrm{M})$ on the degradation of colistin.

The degradation rate was found to increase and $t_{1 / 2}$ decreases with increased time and alkali concentration.

Higher concentrations of sodium hydroxide resulted in the immediate disappearance of the colistin peak and the appearance of the degradation products peaks.

Using hydrochloric acid, the concentration and first derivative spectrum of colistin sulphate were not affected with the different concentrations of acid even at high temperatures.

5.3.3. Effect of Temperature. The developed first derivative method was applied to monitor the time-course decomposition of colistin in phosphate buffer $(\mathrm{pH}$ 9) at temperatures 
TABLE 4: $K, t_{1 / 2}$, and $t_{90}$ values for colistin degradation at $\mathrm{pH} 9$ at different temperatures $\left(5,25\right.$, and $\left.40^{\circ} \mathrm{C}\right)$.

\begin{tabular}{lccc}
\hline Temp. & $K\left(\mathrm{~min}^{-1}\right)$ & $t_{1 / 2}(0.693 / K)$ & $t_{90}(0.105 / K)$ \\
\hline $5^{\circ} \mathrm{C}$ & 0.0008 & 866.25 & 131.25 \\
$25^{\circ} \mathrm{C}$ & 0.0079 & 87.70 & 13.30 \\
$40^{\circ} \mathrm{C}$ & 0.035 & 19.80 & 3.00 \\
\hline
\end{tabular}

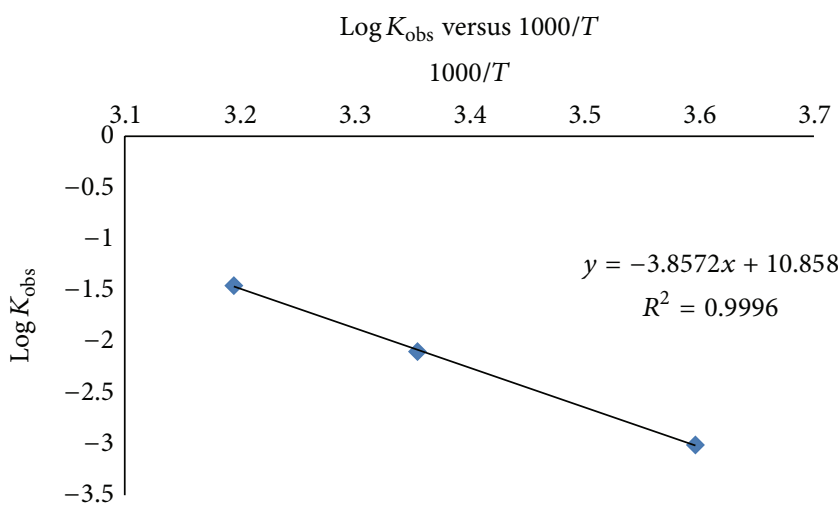

FIGURE 8: Arrhenius plot for degradation of colistin sulphate in phosphate buffer $\mathrm{pH} 9$ and temperatures $5^{\circ}, 25^{\circ}$, and $40^{\circ} \mathrm{C}$.

of $5^{\circ} \mathrm{C}, 25^{\circ} \mathrm{C}$, and $40^{\circ} \mathrm{C}$. The linearity of the constructed plots at different temperatures (log \% remaining drug versus time) reflected the dependence of the decomposition reaction on temperature. The activation energy $\left(E_{a}\right)$ was calculated (18.5 $\mathrm{Kcal} \mathrm{mol}^{-}$) using Arrhenius plot (Figure 8), which was then utilized to calculate the shelf life $\left(t_{1 / 2}\right)$ and $t_{90}$ for colistin sulphate at different temperatures (Table 4).

5.3.4. Effect of Light (Photodegradation). The effect of light is often considered an important factor in drug stability. The photodegradation study on colistin was intended to obtain useful information about the sensitivity of the drug to light. Conditions of irradiation were controlled to study the effect of light and not energy (heat). The decomposition of irradiated colistin solution with sunlight for about 6 hours was monitored using first derivative spectrophotometry. The solution remained stable and there was no change neither in spectrum maximum at $298 \mathrm{~nm}$ nor in the concentration. This reflected the stability of colistin solution under these conditions.

\section{Conclusion}

In this work, simple, accurate, precise, and stabilityindicating spectrophotometric methods were developed for the analysis of colistin sulphate in bulk and dosage forms. The degradation product peak was well separated using the developed first derivative spectrophotometric method.

Colistin sulphate was found to undergo hydrolysis which appeared to be $\left[\mathrm{OH}^{-}\right]$dependent. It was stable along the acidic $\mathrm{pH}$ even at temperatures above $40^{\circ} \mathrm{C}$. Colistin sulphate was found to be photostable under the study conditions.
The developed methods can be useful for the routine quality control analysis and stability study of colistin sulphate.

\section{Conflict of Interests}

The authors declare that there is no conflict of interests regarding the publication of this paper.

\section{References}

[1] M. E. Falagas, A. P. Grammatikos, and A. Michalopoulos, "Potential of old-generation antibiotics to address current need for new antibiotics," Expert Review of Anti-Infective Therapy, vol. 6, no. 5, pp. 593-600, 2008.

[2] A. R. Genaro, The Science and Practice of Pharmacy, Lippincott Williams \& Wilkins, Philadelphia, Pa, USA, 20th edition, 2000.

[3] B. C. Grande, M. S. G. Falcón, C. Pérez-Lamela, M. R. Comesaña, and J. S. Gándara, "Quantitative analysis of colistin and tiamulin in liquid and solid medicated premixes by HPLC with diode-array detection," Chromatographia, vol. 53, pp. 460-463, 2001.

[4] D. Decolin, P. Leroy, A. Nicolas, and P. Archimbault, "Hyphenated liquid chromatographic method for the determination of colistin residues in bovine tissues," Journal of Chromatographic Science, vol. 35, no. 12, pp. 557-564, 1997.

[5] P. Pérez-Lozano, E. García-Montoya, A. Orriols, M. Miñarro, J. R. Ticó, and J. M. Suñé-Negre, "Application of a validated method in the stability study of colistin sulfate and methylparaben in a veterinary suspension formulation by high-performance liquid chromatography with a diode array detector," Journal of AOAC International, vol. 90, no. 3, pp. 706714, 2007.

[6] J. A. Orwa, C. Govaerts, K. Gevers, E. Roets, A. Van Schepdael, and J. Hoogmartens, "Study of the stability of polymyxins B1, E1 and E2 in aqueous solution using liquid chromatography and mass spectrometry," Journal of Pharmaceutical and Biomedical Analysis, vol. 29, no. 1-2, pp. 203-212, 2002.

[7] A. H. Beckkett and J. B. Stenlake, Practical Pharmaceutical Chemistry, part 2, 4th edition, 1997.

[8] Delloyd's Lab Tech resources reagents and solutions, February 2014, http://delloyd.50megs.com/.

[9] M. E. M. Saed, S. W. Shantier, and E. A. Gadkariem, "Development and validation of HPLC method for determination of dexamethasone in animal products and feeds," Journal of Chemical, Biological and Physical Sciences Section A : Chemical Sciences, vol. 5, no. 3, pp. 2751-2761, 2015.

[10] J. C. Miller and J. N. Miller, Statistics and Chemometrics for Analytical Chemistry, Pearson Education Limited, London, UK, 5th edition, 2005.

[11] J. T. Carstensen, Drug Stability Principles and Practices, Marcel Dekker, New York, NY, USA, 2nd edition, 1995.

[12] ICH harmonized tripartite guideline, guidance for industry, stability testing of new drug substances and products, U.S. Department of Health and Human Services, Food and Drug Administration, CDER \& CBER, 2003. 

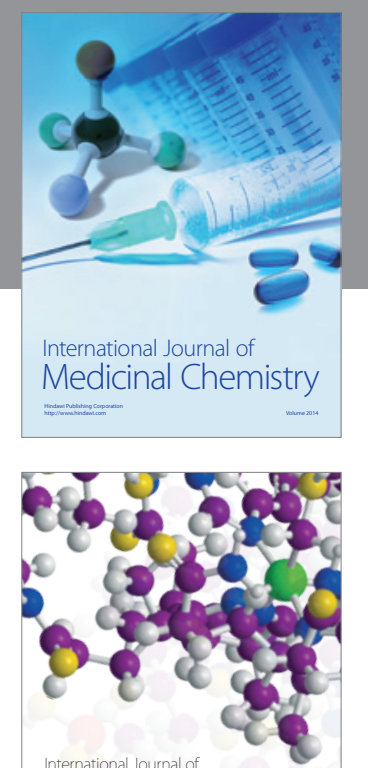

\section{Carbohydrate} Chemistry

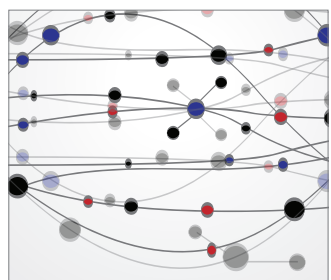

The Scientific World Journal
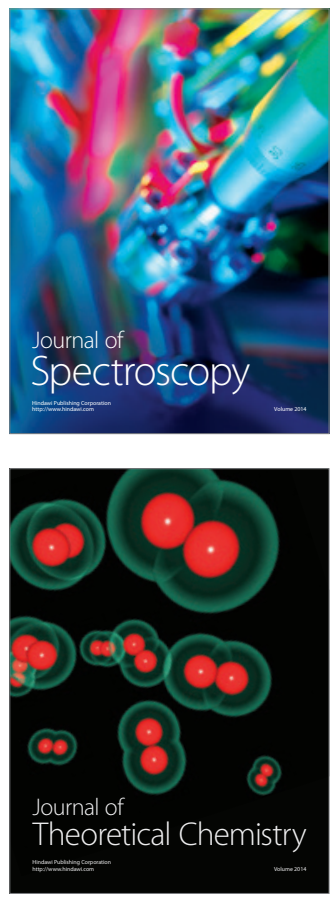
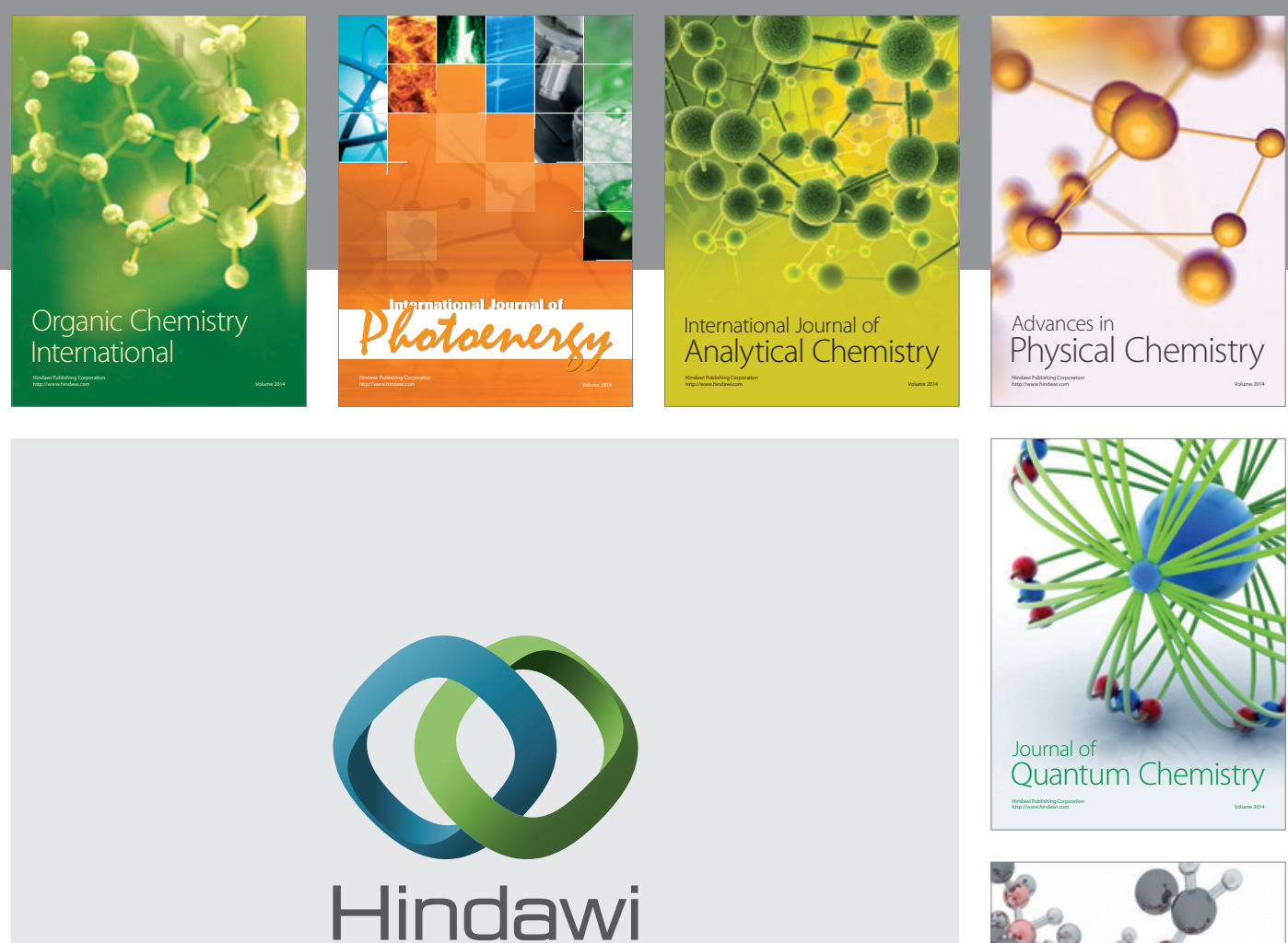

Submit your manuscripts at

http://www.hindawi.com

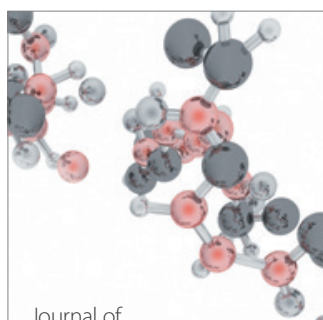

Analytical Methods

in Chemistry

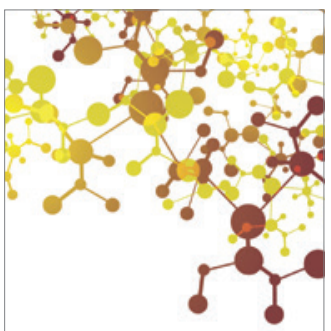

Journal of

Applied Chemistry

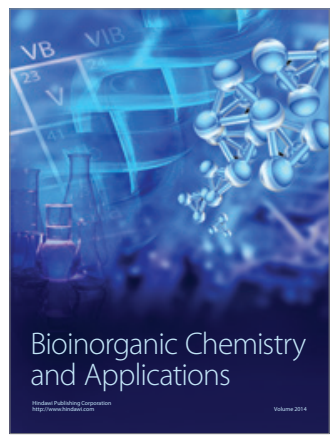

Inorganic Chemistry
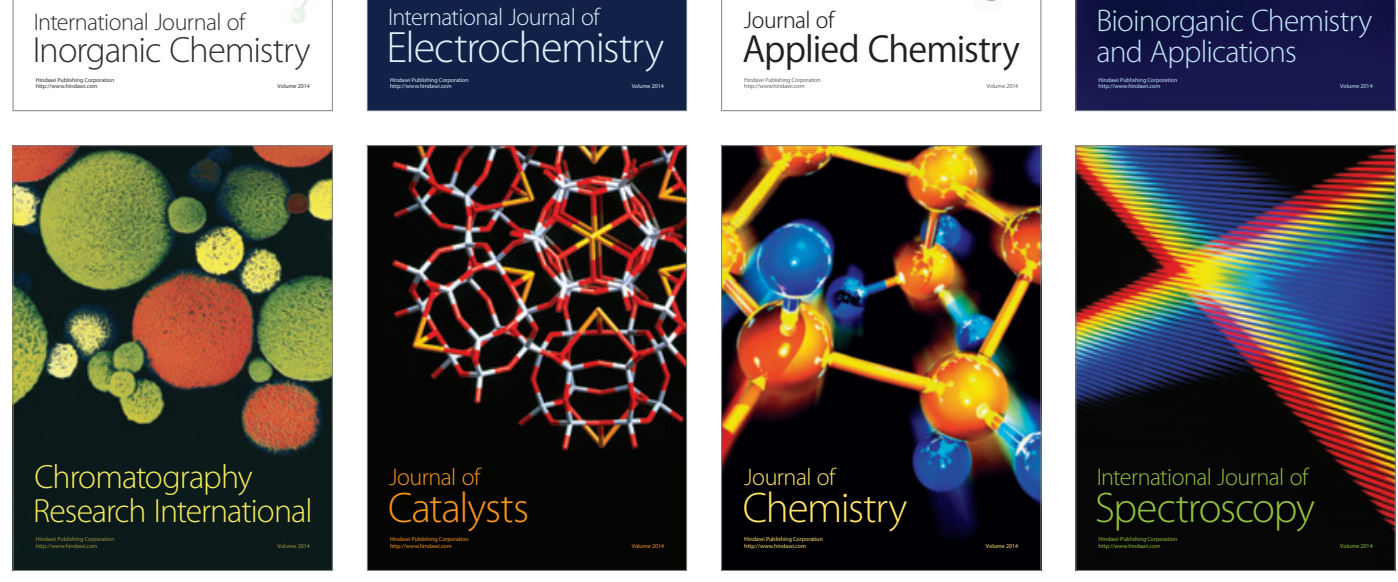